\title{
MODELO CONCEITUAL DE EXPLORAÇÃO AGROPASTORIL PARA O SEMIÁRIDO NORDESTINO
}

\author{
MODELO CONCEPTUAL DE EXPLOTACIÓN AGRÍCOLA PARA LA REGIÓN \\ SEMIÁRIDA NORESTE
}

\section{CONCEPTUAL MODEL OF AGRICULTURAL EXPLORATION FOR THE NORTHEASTERN SEMIARID REGION}

\author{
Malaquias BATISTA FILHO ${ }^{1}$ \\ Rachel de Sá Barreto Luna Callou CRUZ ${ }^{2}$
}

\begin{abstract}
RESUMO: A renda básica deve assegurar condições favoráveis à saúde, o direito de escolha e pleno exercício de um trabalho profissional validado cultural e eticamente; uma dimensão ambiental, ética, co-participativa e, juntando todos esses elementos básicos, a questão da sustentabilidade. No entanto, estas metas se tornam desafiadoras para o pequeno proprietário no cenário habitual do semiárido: solos pobres, pouca chuva, pouca água, muito sol, pouca umidade do ar, evaporação nas alturas e balanço hídrico negativo. Situação agravada ainda pela geografia física e humana da pobreza. Nesse sentido, este estudo faz uma breve reflexão sobre um modelo conceitual de exploração agropastoril em pequenas propriedades do semiárido nordestino. A descrição propositiva é hipotética, sendo uma representação de conceitos e propostas idealizadas, embora plenamente possíveis por lógica expositiva e sua validação por observações empíricas.
\end{abstract}

Palavras-chave: Pequenas propriedades. Semiárido. Exploração agropastoril. Sustentabilidade.

RESUMEN: La renta básica debe asegurar condiciones favorables para la salud, el derecho de elección y pleno ejercicio de un trabajo profesional culturales validado y éticamente; una dimensión ambiental, la ética, la co-participación y unión de todos estos elementos básicos, el tema de la sostenibilidad. Sin embargo, estos objetivos se convierten en un reto para el pequeño propietario en el escenario habitual semiárido: suelos pobres, escasas precipitaciones, muy poca agua, demasiado sol, baja humedad, la evaporación en el balance más alta y negativa agua. Situación agravada aún más por la geografía física y humana de la pobreza. En este sentido, este estudio hace una breve reflexión sobre un modelo conceptual de las explotaciones agropecuarias en pequeñas propiedades del nordeste semiárido. La descripción propósito es hipotético y es una representación de conceptos y propuestas

\footnotetext{
${ }^{1}$ PhD em Saúde Pública pela USP; Professor Emérito da UFPE e UFBA; Docente e pesquisador do Instituto Medicina Integral Prof. Fernando Figueira-IMIP. Recife, Pernambuco, Brasil. E-mail: malaquias.imip@gmail.com

${ }^{2}$ Doutorado em andamento em Saúde Materno Infantil pelo Instituto de Medicina Integral Prof. Fernando Figueira-IMIP. Ms. em Desenvolvimento Regional Sustentável-UFC. E-mail: rachel.callou@hotmail.com
} 
idealizadas, en el pleno la posible lógica expositiva y su validación por las observaciones empíricas.

Palabras clave: Edificios pequeños. Semiáridas. explotación agropastoral. Sostenibilidad.

ABSTRACT: The basic income must ensure conditions favorable to health, the right of choice and full exercise of a validated cultural professional work and ethically; an environmental dimension, ethics, co-participatory and joining all these basic elements, the issue of sustainability. However, these goals become challenging for the small landowner in the semiarid usual scenario: poor soils, little rain, too little water, too much sun, low humidity, evaporation in the highest and negative water balance. Aggravated further by physical geography and human geography of poverty. In this sense, this study reflects on a conceptual model of agropastoral holdings in small properties of the semiarid northeast. The purposeful description is hypothetical and is a representation of idealized concepts and proposals, while fully possible for expository logic and its validation by empirical observations.

Keywords: Small property. Semiarid. Agropastoral exploitation. Sustainability.

\section{INTRODUÇÃO}

A grande maioria (na realidade, mais de 60\%) das propriedades rurais do semiárido nordestino são representadas por sítios ou parcelas de terras com menos de 50 hectares, o que, segundo consenso do público, seria, em princípio, insuficiente para produzir uma renda mensal de um salário mínimo. Ou seja, um ativo econômico capaz de suprir as demandas básicas de moradia, energia elétrica, alimentação, transporte, vestuário, saúde e educação.

Atender simultaneamente todos estes itens com um salário mínimo já é um problema e tanto. Imagine-se então o desafio de manter uma família padrão, vamos dizer, um casal de pais e dois filhos menores, com renda abaixo de um salário mínimo familiar. E isto não é uma conjectura, mas a realidade do dia a dia de milhões de famílias rurais do Nordeste semiárido que ganham menos de 1/4 de salário mínimo per capita (ou 0,25 SM). Assim está posto o dilema da pequena propriedade e da baixa renda familiar no semiárido do Nordeste Brasileiro. Como encaminhar o problema? Dividir as grandes propriedades em pequenos módulos fundiários, como vem sendo feito, e assim cair na inviabilidade da geração de renda adequada para atender o orçamento básico das famílias alocadas nos minifúndios? Ou fazer a reforma agrária ao contrário, agregando lotes pequenos de terra em módulos maiores de 100, $150 \mathrm{ou}$ 200 hectares? Ou, na mesma lógica, redistribuir os latifúndios em lotes de tamanho médio, 
contornando as restrições da mini e pequena propriedade?

São pontos de partida mas, necessariamente, não são metas de chegada ou objetivos finais. Os desfechos bem sucedidos nos projetos de desenvolvimento devem contemplar vários enfoques, como meios ou fins do progresso humano em suas diferentes configurações. Ou seja, deve assumir uma dimensão econômica, com um horizonte acima da linha crítica da pobreza/indigência que discrimina a exclusão do mercado; uma dimensão social que estenda e diversifique as funções da economia, multiplicando os usofrutos do progresso, como a educação básica, com canais abertos para outros corredores e habilidades profissionais, intelectuais e artísticas; uma dimensão política que representa o próprio mandato de cidadania assegurado pelas leis, normas, valores e costumes de cada sociedade. A renda básica deve assegurar condições favoráveis à saúde, o direito de escolha e pleno exercício de um trabalho profissional validado cultural e eticamente; uma dimensão ambiental, ética, co-participativa e, juntando todos esses elementos básicos, a questão da sustentabilidade. São os referenciais que servem de suporte a uma doutrina consistente, desafiadora e viável de desenvolvimento humano (ALVES, 2008; SCHAPPO, 2008; TARANTO, 1993).

\section{PEQUENAS PROPRIEDADES}

A descrição propositiva que se segue é hipotética, uma representação de conceitos e propostas idealizadas, embora plenamente possíveis por lógica expositiva e sua validação por observações empíricas. Suponha-se um plantel de 100 matrizes (cabras ou ovelhas em idade reprodutiva) e dois machos reprodutores. Este pequeno rebanho devidamente cuidado, pode produzir de 120 a 140 crias anuais que, vendidas aos oito meses de vida, a 150 reais cada, resultam num ativo de 18.000,00 a 21.000,00 reais/ano. Ou seja, o equivalente mensal de $1.500,00$ a $1.750,00$ reais brutos.

Vamos admitir uma perda mensal de $10 \%$ por conta de mortes no rebanho, mais $15 \%$ de custos extras: vacinas, outros medicamentos de uso veterinário, suplementos ou complementos alimentares, como sais minerais ou concentrados proteicos. Portanto, $25 \%$ para as duas parcelas negativas juntas. Com esta conta, teríamos um custo embutido de 1/4, ou seja, $25 \%$ do valor de mercado de cada animal. Reajustado para o orçamento anual, seria o equivalente a 375,00 reais para a primeira exemplificação (120 animais vendidos) e 437,00 reais para a segunda estimativa (140 animais comercializados). É o vermelho da 
contabilidade.

Assim, na primeira hipótese, feito o desconto de 25\%, o ativo anual seria de $13.500,00$ reais, enquanto na segunda alcançaria de 18.500,00 reais. Convertendo estes valores em rendimentos mensais, resultaria em 1.125,00 reais para a primeira condição, representando, portanto, uma renda média acima de um salário mínimo (780,00 reais). Já para o exemplo de menor rendimento anual, ou seja, para o segundo cenário teríamos $1.312,00$ mensais para a alternativa de maior renda bruta. Numa ou noutra situação, a renda seria $40 \%$ ou $50 \%$ acima do salário mínimo praticado no Brasil. Portanto, em princípio, estaria assegurada uma renda significativamente maior que um salário mínimo, que é a questão preliminar colocada em discussão. Na conclusão destas contas, seria viável uma renda mais que segura de um salário mínimo por família de sertanejos e agresteiros que formam as populações rurais de nosso semiárido, garantindo, ainda, o extra do $13^{\circ}$ mês e o adicional de $30 \%$ para um mês de férias, como preconiza a legislação trabalhista. E este resultado, por razões históricas e por lógica conceitual, é a própria justificativa da segurança alimentar e nutricional, expressa no salário mínimo. Mas, como manter 100 matrizes em produção de carne ou leite, como retaguarda (ou vanguarda?) para se ganhar um salário mínimo, como condição básica de segurança alimentar?

\section{A CONTA E CONTEXTO}

O contexto é o cenário habitual do semiárido: solos pobres, pouca chuva, pouca água, muito sol, pouca umidade do ar, evaporação nas alturas e balanço hídrico negativo. Para agravar a geografia física, a geografia humana da pobreza: a crença mística no sobrenatural, decidindo a sorte de cada um, a ideia da salvação da alma pelo sofrimento do corpo, a miragem da felicidade eterna depois das dores eternas enquanto dura a vida. Ou esta segunda via - o curandeirismo político, o afilhadismo e o paternalismo, o poder dos homens de elite, a dependência social, as bolsas doadas pelo governos, que são de fato um benefício estratégico para atravessar a pobreza, mas que se tornam um mal se não se encontra uma saída estrutural das “grades estreitas do próprio mundo". Ou seja, quando o pauperismo passa a se cronificar como doença sistêmica, autossustentável, quase hereditária, transferindo-se de avós para pais e filhos como um legado que passa pela experiência ou, pelo menos, pela expectativa da fome. 
Propriedades com 70 hectares, pouco mais ou menos, fazem parte dessa condenação estrutural à pobreza e a indigência? Um salário mínimo, como linha de separação desse “apartheid", pode ser uma porta de saída? Dois hectares cultivados pode representar a chave de abertura desta porta?

Provavelmente sim. Dois hectares plantados com palma resistente à seca e à praga representam um suporte decisivo. Por exemplo, a "orelha de elefante" pode produzir 1.200 toneladas anuais de massa alimentar em dois hectares. É o suficiente para uma base alimentar (50\% da ração volumosa) de 100 cabras ou ovelhas e suas crias durante a estiagem. Vamos dizer, um "per capita” de 1,5 a 3 quilos dia. Dentro desses dois hectares podem ainda ser plantados 100 a 200 pés de algaroba que, como uma boa "juliflora," safreja entre outubro e dezembro, no calendário mais crítico da seca. É um auxílio salvador. A algaroba pode formar uma dupla com a leucena, que tem a vantagem de uma produção quase contínua de vagens ao longo do ano, sem a limitação de uma safra por estação. As duas juntas podem trazer uma contribuição considerável como concentrado, ou seja, como suporte proteico da alimentação do rebanho. Com qualquer ajudinha, como farelos industrializados, pitadas de ureia bem manipuladas, mesclas de compostos nitrogenados e até a sofisticada (mas, barata) multimistura da EMEPA/PB, podem, a baixo custo, complementar uma ração balanceada. Tudo isto, incluindo uma farmácia básica de vacinas, vermífugos, antibióticos, soro oral, estratos placentários, cabe na estimativa de $15 \%$ já mencionada.

É bom dispor de uma “conta" ou qualquer coisa como um quadrado de 20 por 20 braças de capim elefante, que permite três a quatro cortes anuais de ração fresca de 150-200 gramas diários para cada animal, no tempo das cabras magras. Seria uma excelente "sobremesa".

Claro, não se pode esquecer o acesso à uma fonte de água, seja para uso doméstico, para consumo animal ou para irrigação quinzenal de uma conta de capim. Cisternas de captação de águas de chuvas, cisternas naturais em formações rochosas, barreiros, poços profundos, localização e captação de lençóis freáticos, barragens submersas que, por sua importância, já tem sido devidamente divulgadas e difundidas (ver o programa "um milhão de cisternas", por exemplo), são amplamente conhecidas e apoiadas como programas de governo.

Em tempo: os estrumes de chiqueiros e capris podem e devem ser removidos para adubar a palma e o capim. Afinal, não se pode retirar seguidamente 600 a 1.200 toneladas de ração sem devolver nada ao solo. E outra informação ou recomendação: nas "ruas"de palma pode se plantar milho e feijão macássar ou guandu. Se chover bem, obtém-se dois subprodutos (ou melhor, dois alimentos)para entrar no circuito de segurança alimentar.Se não 
chover, os caprinos agradecem pela disponibilidade dos restolhos.

Também em tempo: um homem, que seja medianamente diligente (preguiçoso não conta), pode cuidar muito bem desses dois hectares e seu rebanho de 100 matrizes sem maiores atropelos. E ainda em tempo: este esboço de proposição é uma idealização básica, não uma receita mágica que resolve todas as situações. Com inteligência e operosidade podese buscar modelos mais criativos ou mais ajustados às pendências de cada local e de cada família (SILVEIRA; PETERSON; SABOURIN, 2002; SCHUMACHER, 1983). Fica a proposta.

\section{REFERÊNCIAS}

ALVES, J.J.A. Ano Centenário de Josué de Castro-61 Anos da Geografia da Fome. Revista Espaço Acadêmico, n. 89, outubro de 2008.

SCHAPPO, Sirlândia. Josué de Castro: por uma agricultura de sustentação. Tese (Doutorado em Sociologia) - Unicamp, Campinas, 2008.

SCHUMACHER, E.F (Tradução). O negócio é Ser Pequeno. Um estudo de economia que leva em conta as pessoas. $4^{\mathrm{a}}$ ed. Rio de Janeiro: Zahar, 1983.

SILVEIRA, L.; PETERSON, P.; SABOURIN, E. Agricultura familiar e agroecologia no Semiárido: avanços a partir do agreste da Paraíba. Rio de janeiro: AS-PTA, 2002.

TARANTO, Giuseppe A. Sociedade e subdesenvolvimento na obra de Josué de Castro. Belém: CEJUP, 1993. 